\title{
Alpha Variant Selection Determined from Grain Misorientations in Ti-6Al-7Nb Alloy with a Duplex Microstructure
}

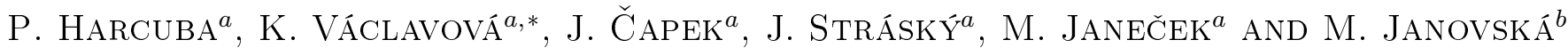 \\ ${ }^{a}$ Department of Physics of Materials, Charles University in Prague, Ke Karlovu 5, 121 16, Prague, Czech Republic \\ ${ }^{b}$ Academy of Sciences of the Czech Republic, Institute of Thermomechanics, Prague, Czech Republic
}

\begin{abstract}
Titanium occurs in two structures; a high temperature body-centered cubic structure which is known as $\beta$ phase and an ambient temperature $\alpha$ phase which has the hexagonal closed-packed structure. In the present study a biomedical $\mathrm{Ti}-6 \mathrm{Al}-7 \mathrm{Nb}$ alloy was investigated. The so-called duplex structure consisting of $\alpha$ lamellae and equiaxed primary $\alpha$-grains was prepared by a thermal treatment. The $\alpha$ lamellae are created during cooling from a $\beta$-field according to the Burgers relation. This relation allows the formation of the $\alpha$ lamellae with different crystallographic orientations - so-called variants. The preferential misorientation between $\alpha$ lamellae was studied by a detailed electron backscattered diffraction analysis. The misorientation of grains in the duplex structure was modelled by a sum of random Mackenzie distribution and Gaussian peaks related to the preferred misorientations according to the Burgers relation. The preferred misorientations based on the Burgers relationship were identified in the biomedical $\mathrm{Ti}-6 \mathrm{Al}-7 \mathrm{Nb}$ alloy with duplex structure. It is confirmed that the variant selection of $\alpha$ lamellae is not random.
\end{abstract}

DOI: 10.12693/APhysPolA.128.570

PACS: 61.66.Dk, 61.72.Mm, 68.37.-d

\section{Introduction}

Titanium and titanium alloys are the mostly used materials for orthopaedic implants, due to their excellent mechanical properties and biocompatibility [1]. The most common alloy is $\mathrm{Ti}-6 \mathrm{Al}-4 \mathrm{~V}$ alloy developed for aerospace use in the 1950s. A Ti-6 Al-7Nb alloy containing biocompatible niobium instead of toxic vanadium was developed as a biocompatible alternative. Titanium is a polymorphic material. Above the so-called $\beta$-transus temperature the material consists purely of the $\beta$ phase (bcc structure), which after cooling transforms to the $\alpha$ phase (hcp structure). Both mentioned alloys belong to the group of $\alpha+\beta$ alloys that contain both phases at room-temperature. During sufficiently fast cooling, the $\alpha$ lamellae are created inside the $\beta$-grains by a martensitic transformation. The final structure is then referred to as lamellar microstructure. This martensitic $\beta \rightarrow \alpha$ transformation follows the Burgers orientation relations between the two phases [2]:

$$
(110)_{\beta} \|(00.2)_{\alpha} \text { and }[-11-1]_{\beta} \|[2-1.0]_{\alpha} \text {. }
$$

It is known that according to the Burgers relationship and the symmetry of the $\alpha$ and $\beta$ phases, a total of 12 different $\alpha$ orientations (12 variants) may arise from an initial $\beta$ orientation during the $\beta \rightarrow \alpha$ transformation [3-5].

The crystallographic orientation of the $\alpha$ lamellae can be identified for instance by electron backscattered diffraction (EBSD). Measured crystallographic orientation obviously depends on the orientation of an original

\footnotetext{
* corresponding author; e-mail: kristina.vaclavova@gmail.com
}

$\beta$-grain, but the mutual orientation (misorientation) between two $\alpha$ lamellae which originated from the same $\beta$ grain can be computed for all pairs of the $\alpha$ variants. This analysis was done in $[3,4,6]$ and the possible misorientations between $\alpha$ variants fulfilling the Burgers relationship are of $10.5^{\circ}, 60^{\circ}, 60.83^{\circ}, 63.26^{\circ}, 90^{\circ}$. Furthermore, if we assume that the $\alpha$ variants are created randomly, the expected ratio of the misorientations listed above can be computed as $2: 3: 2: 2: 1$ [7].

A slightly more complicated microstructural condition (so-called duplex microstructure) is investigated in this study. By annealing below the $\beta$-transus temperature [8], it is possible to create equiaxed primary $\alpha$-grains which are formed by the nucleation and growth mechanism. The orientations of those grains therefore do not follow any Burgers relationship and have no special relation to their neighbours. Orientation of the primary $\alpha$-grains is therefore assumed to be random and the misorientations related to the primary $\alpha$-grains obey the random (Mackenzie) distribution [9]. As a result, the measured distribution of misorientations (that is the main experimental result of this study) is a sum of the random Mackenzie distribution due to the primary $\alpha$-grains (and also misorientations of the $\alpha$ lamellae belonging to different parent $\beta$-grains) and the peaks corresponding to the special misorientations between the $\alpha$ lamellae.

\section{Materials and methods}

The investigated titanium alloy was the biomedical $\alpha+\beta$ Ti-6Al-7Nb alloy. Its $\beta$-transus temperature is $1010^{\circ} \mathrm{C}$ [10]. The material was supplied by ATI Alvac according to ASTM F 1295 standard in the as-annealed condition. As-received material consists of the duplex microstructure with a high content of the primary $\alpha$-grains 
(not shown). Such a structure would not allow analyzing misorientations of the $\alpha$ lamellae since the volume fraction of the lamellar part is too low. The material was therefore further thermally treated. The procedure consisted of recrystallization annealing at $985{ }^{\circ} \mathrm{C}$ for one hour followed by quenching to room temperature and an annealing at $700^{\circ} \mathrm{C}$ for $4 \mathrm{~h}$ followed by air cooling. The lamellar structure is created during the quenching after the high temperature annealing. The next annealing step creates the equiaxed primary $\alpha$-grains. In the $\mathrm{Ti}-6 \mathrm{Al}-7 \mathrm{Nb}$ alloy after the thermal treatment, the volume fraction of primary $\alpha$-grain was $18 \%$ and the average size of the primary $\alpha$-grains was $5.3 \mu \mathrm{m}$.

Direct observations of the microstructure of the specimen were accomplished by scanning electron microscope FEI Quanta 200F. EBSD was used for analyzing grain orientations. The EBSD camera DigiView3 by EDAX and the TSL OIM 5 software were used for signal acquisition and data analysis. To our knowledge, this is the first time that the $\alpha$-variant selection was investigated for duplex structure and also for the $\mathrm{Ti}-6 \mathrm{Al}-7 \mathrm{Nb}$ alloy.

\section{Results}

The microstructure of the material is shown in Fig. 1. The duplex structure of the alloy is well-visible in BSE signal thanks to the element partitioning. The bigger and darker grains indicated by $\mathrm{A}$ in the figure containing more $\mathrm{Al}$ are the primary $\alpha$-grains. The $\alpha$ lamellae in the so-called $\alpha+\beta$ region (B) are observable while the thin $\beta$ particles between the lamellae are visible only in a higher magnification image (not shown). Slightly bigger $\beta$-phase particles surround the primary $\alpha$-grains $(\mathrm{C})$ and appear white due to vanadium enrichment.

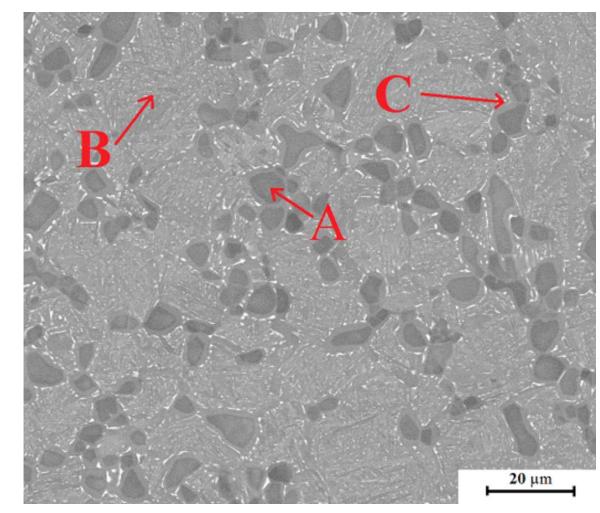

Fig. 1. Overview SEM image of the sample (For A, B, C see text).

Figure 2 shows the inverse pole figure map of the $\mathrm{Ti}-6 \mathrm{Al}-7 \mathrm{Nb}$ alloy and the orientation triangle for the hexagonal close packed structure. The duplex character of the material is clearly observable from the EBSD image, but no $\beta$ phase was identified due to the fact that the step size of the EBSD measurement was comparable to the $\beta$ phase particles size. By careful observation, it can be found out that in a given location, the lamellae

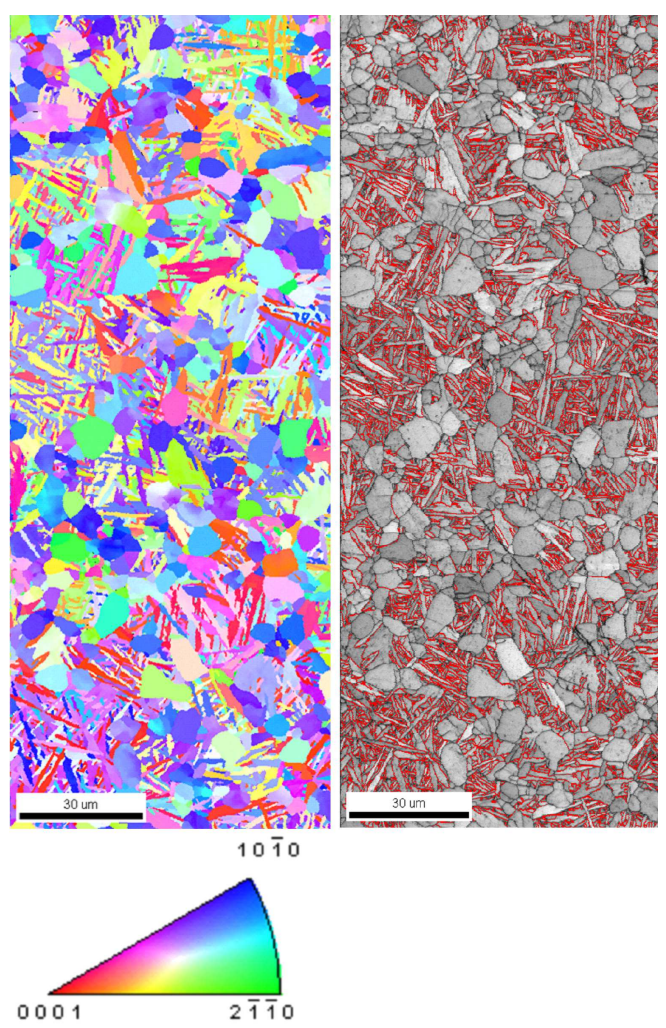

Fig. 2. (top left) Inverse pole map figure of Ti-6Al$7 \mathrm{Nb}$; (top right) image quality picture from EBSD data (gray background showing grain boundaries). Grain boundaries with misorientations in the range of $55^{\circ}-65^{\circ}$ (mostly between alpha lamellae in the alpha + beta region) are shown in red; (bottom) orientation triangle for the $\alpha$ titanium (hcp structure).

elongated in the same direction often have the same color (orientation). These lamellae are the same variant from a single $\beta$-grain. It is therefore argued that the direction of the lamella is associated with its crystallographic orientation (i.e. variant selection).

In Fig. 2, grain boundaries with misorientations in the range of $55-65^{\circ}$ are highlighted by red color. It is clearly visible that red-highlighted grain boundaries with misorientations between $55^{\circ}-65^{\circ}$ are often preferred between two lamellae. On the other hand, the misorientation between an equiaxed primary $\alpha$-grain and its neighbours usually does not belong to the highlighted range.

Figure 3 shows the distribution of the misorientations between grains (black curve). The misorientation data are evaluated with a step of $0.25^{\circ}$. The seeming background is caused by the primary $\alpha$-grains that are randomly oriented. Therefore the Mackenzie distribution (blue curve) must be a part of the fit. The obvious peaks of preferred misorientation are fitted using four Gaussian distributions. It is clear that the misorientations around $10.5^{\circ}, 60^{\circ}, 63^{\circ}$ and $90^{\circ}$ are preferred.

\section{Discussion}

An efficient approach to compute the misorientation angles between different variants of the $\alpha$ lamellae 


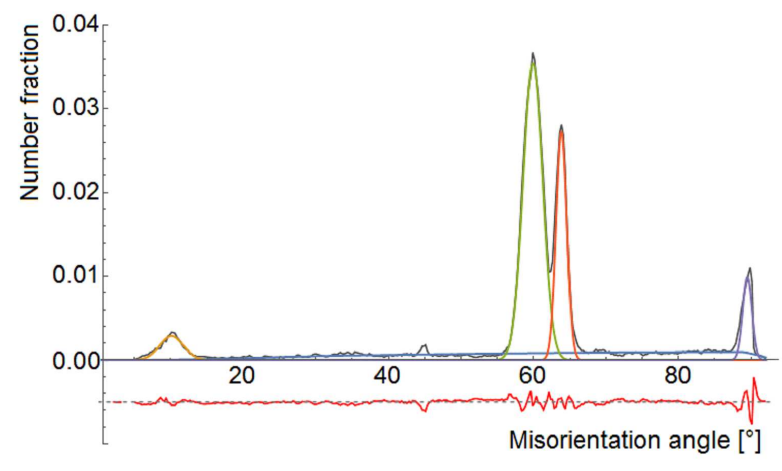

Fig. 3. Misorientations distribution acquired from EBSD (black curve). Fit of the Mackenzie distribution (blue curve) and four Gaussian peaks. The red line below the plot shows the difference between the data and the sum of the fitted curves.

obeying the Burgers relationship is described in [3]. The appropriate angles of misorientation are $10.5^{\circ}, 60^{\circ}$, $60.83^{\circ}, 63.26^{\circ}, 90^{\circ}$. It is clear from Fig. 3 that the peak around $60^{\circ}$ can be separated into two peaks and the theoretically predicted peaks for angles of $60^{\circ}$ and $63.26^{\circ}$ can be distinguished. In results from the literature, these peaks are predicted, but they are not distinguishable experimentally $[7,11]$. On the other hand, peaks for angles of $60^{\circ}$ and $60.83^{\circ}$ are too close to be distinguished even from our results.

The fit of the distribution of grain misorientations was done using Mathematica 8.0. The function of the fit is the sum of the Mackenzie distribution and 4 or 5 Gaussian peaks that have either pre-defined means according to the theory or the means of the peaks are regarded as the fitting parameters (respectively fixed means vs. free means). The intensity of the Mackenzie distribution and intensity of peaks were fitted. The $R$-squared statistics shows the quality of the fit. The portion of the random Mackenzie distribution was calculated from the relative intensity of the Mackenzie distribution when compared to the sum of the intensities of peaks and the Mackenzie distribution. Afterwards, the intensities of the peaks were renormalized to sum up to $100 \%$.

TABLE

Fitting of distribution of $\alpha$-grain misorientations.

\begin{tabular}{|c|c|c|c|c|c|}
\hline & $\begin{array}{l}\text { Fit } 1-5 \text { peaks, } \\
\text { free mean value }\end{array}$ & $\begin{array}{l}\text { Fit } 2-5 \text { peaks, } \\
\text { fixed mean value }\end{array}$ & $\begin{array}{l}\text { Fit } 3-4 \text { peaks, } \\
\text { free mean value }\end{array}$ & $\begin{array}{l}\text { Fit } 4-4 \text { peaks, } \\
\text { fixed mean value }\end{array}$ \\
\hline & $R$-squared & 0.997 & 0.941 & 0.997 & 0.941 \\
\hline & Mackenzie & $21.3 \%$ & $26.7 \%$ & $20.9 \%$ & $27 \%$ \\
\hline peak 1 & $\begin{array}{l}\text { mean value }\left[{ }^{\circ}\right] \\
\text { intensity }\end{array}$ & $\begin{array}{l}10.12 \\
6.1 \%\end{array}$ & $\begin{array}{c}10 \\
6.0 \%\end{array}$ & $\begin{array}{l}10.12 \\
6.1 \%\end{array}$ & $\begin{array}{c}10 \\
6.5 \%\end{array}$ \\
\hline peak 2 & $\begin{array}{c}\text { mean value }\left[{ }^{\circ}\right] \\
\text { intensity }\end{array}$ & $\begin{array}{c}58.77 \\
15.3 \%\end{array}$ & $\begin{array}{c}60 \\
56.0 \%\end{array}$ & $\begin{array}{l}59.92 \\
60.4 \%\end{array}$ & $\begin{array}{c}60 \\
55.4 \%\end{array}$ \\
\hline peak 3 & $\begin{array}{l}\text { mean value }\left[{ }^{\circ}\right] \\
\text { intensity }\end{array}$ & $\begin{array}{l}60.31 \\
44.4 \%\end{array}$ & $\begin{array}{c}60.83 \\
0 \%\end{array}$ & $\begin{array}{l}63.86 \\
25.4 \%\end{array}$ & $\begin{array}{c}63.26 \\
30.4 \%\end{array}$ \\
\hline peak 4 & $\begin{array}{l}\text { mean value }\left[{ }^{\circ}\right] \\
\text { intensity }\end{array}$ & $\begin{array}{c}63.84 \\
26.0 \%\end{array}$ & $\begin{array}{c}63.26 \\
30.4 \%\end{array}$ & & \\
\hline peak 5 & $\begin{array}{c}\text { mean value }\left[{ }^{\circ}\right] \\
\text { intensity }\end{array}$ & $\begin{array}{l}89.48 \\
8.2 \%\end{array}$ & $\begin{array}{c}90 \\
7.6 \%\end{array}$ & $\begin{array}{l}89.48 \\
8.1 \%\end{array}$ & $\begin{array}{c}90 \\
7.6 \%\end{array}$ \\
\hline
\end{tabular}

In the Table the results of the different fits are shown. The intensities are normalized to the sum of intensities. The fit includes either five peaks as described by the theory or four peaks that is more plausible from the data. Similarly, the means of the peaks are either fixed or they are freely chosen as fitting parameters $[7,11]$. The fit for 5 peaks is not very successful and the distinction between peaks at $60^{\circ}$ and $60.8^{\circ}$ is purely artificial and not plausible. On the other hand, the best fit is achieved for 4 peaks with free mean values of the peaks. In this case the fit is very successful with the $R$-squared of 0.997 . The fit of the peaks is plausible, which is illustrated by the error function below the plot in Fig. 3. The portion of the Mackenzie distribution is $20.9 \%$ - the lowest of the considered fits. The fitted means of peaks are: $10.5^{\circ}$, $59.92^{\circ}, 63.86^{\circ}, 89.48^{\circ}$ which corresponds to the theoretical positions: $10.5^{\circ}, 60^{\circ} / 60.83^{\circ}, 63.26^{\circ}, 90^{\circ}$. The relative abundances of the individual intensities from all intensities are in a row $-10.5^{\circ}, 59.92^{\circ}, 63.86^{\circ}, 89.48^{\circ} \rightarrow 6.1 \%$, $60.4 \%, 25.4 \%, 8.1 \%$. In comparison with the theoretical representation $(10 \%, 20 \%+30 \% \rightarrow 50 \%, 20 \%, 20 \%)$ our results are different. It follows that the variant selection is not random, which is in accordance with the literature [11]. It is reported that these uneven volumefractions of the variants are caused by mutual orientations of original $\beta$-grains $[11,12]$. It is further claimed 
in [4] that low misorientations are preferred. On the other hand, our results show that the misorientations around $10.5^{\circ}$ are less abundant than suggested by random variant selection. This discrepancy might be due to two reasons. First, we omit very low misorientations $\left(<1.5^{\circ}\right)$, because these are often below the misorientations of sub-grains. Second, the authors in [11] may overestimate the effect of the Mackenzie distribution which effectively magnifies the peak at the misorientation of $10.5^{\circ}$.

\section{Conclusions}

In the present study the distribution of grain misorientations in biomedical $\mathrm{Ti}-6 \mathrm{Al}-7 \mathrm{Nb}$ alloy was investigated:

- Misorientations distribution was determined from the high quality EBSD measurement.

- The misorientation distribution was evaluated for the duplex microstructure. The misorientation between the $\alpha$ lamellae is not random and corresponds to the Burger relationship for the martensitic $\beta \rightarrow \alpha$ transformation, whereas the primary $\alpha$-grains are oriented randomly.

- The misorientations peaks at $60 / 60.83^{\circ}$ and $63.26^{\circ}$ were clearly distinguished thanks to the high quality of EBSD measurement.

- The total distribution of the misorientations was successfully fitted using a combination of the Gaussian peaks and the random Mackenzie distribution.

- The relative intensities of misorientation are: $10^{\circ}$ : $60^{\circ} / 60.83^{\circ}: 63.26^{\circ}: 90^{\circ} \rightarrow 6.1 \%: 60.4 \%: 25.4 \%$ : $8.1 \%$, which suggests that the variants of $\alpha$ lamellae orientation are not chosen randomly. This fact is in accordance with the literature.

\section{Acknowledgments}

This work was financially supported by the Czech Ministry of Education and Youth under the grant LH 12217 and by the Czech Science Foundation under the grant 14-36566G.

\section{References}

[1] C. Leyens, M. Peters, Titanium and Titanium Alloys, Wiley-VCH, Germany 2003.

[2] W.G. Burgers, Physica 1, 561 (1934).

[3] T. Karthikeyan, S. Saroja, M. Vijayalakshmi, Scr. Mater. 5, 771 (2006).

[4] N. Gey, M. Humbert, J. Mater. Sci. 38, 1289 (2003).

[5] K. Wang, M.Q. Li, Scr. Mater. 68, 964 (2013).

[6] L.S. Tóth, B. Beausir, C.F. Guc, Y. Estrin, N. Scheerbaum, C.H.J. Davies, Acta Mater. 58, 6706 (2010).

[7] V. Randle, G.S. Rohrerb, Y. Hua, Scr. Mater. 5, 183 (2008).

[8] M. Janeček, J. Stráský, J. Č́žzek, P. Harcuba, K. Václavová, V.V. Polyakova, I.P. Semenova, Metall. Mater. Trans. A 45, 7 (2013).

[9] J.K. Mackenzie, Acta Metall. 12, 223 (1964).

[10] R. Boyer, G. Welsch, E.W. Collings, Materials Properties Handbook, Titanium Alloys, ASM International, USA 1994.

[11] N. Gey, M. Humbert, Acta Mater. 50, 277 (2002).

[12] G.A. Sargent, K.T. Kinsel, A.L. Pilchak, A.A. Salem, S.L. Semiatin, Metall. Mater. Trans. A 43, 3570 (2012). 